\title{
The Possibility of Friction Stir Welding of High Nitrogen-containing Austenitic Stainless Steel
}

\author{
Yasuyuki MIYANO ${ }^{1}$, Hidetoshi FuJII', Yufeng Sun², \\ Kouichi IEKO ${ }^{3}$, Yasuyuki KATADA ${ }^{4}$ and Osamu KAMIYA ${ }^{3}$
}

${ }^{1}$ Faculty of Educational Systems and Studies, Akita University,1-1, Tegatagakuen-machi, Akita-city, AKITA

${ }^{2}$ Joining and Welding Research Institute, Osaka University, 1-1 Yamadaoka, Suita, Osaka 565-0871 Japan

${ }^{3}$ Faulty of Engineering and Resource Science, Akita University, 1-1, Tegatagakuen-machi, Akita-city, AKITA

${ }^{4}$ National Institute for Materials Science, 1-2-1 Sengen, Tsukuba-city Ibaraki 305-0047 JAPAN

E-mail:y.miyano@gipc.akita-u.ac.jp

\begin{abstract}
To develop the practical use of high nitrogen-containing austenitic stainless steels (HNS), the possibility of using friction stir welding (FSW) of HNS was examined. In this report, butt-welding of $2 \mathrm{~mm}$ thick HNS steel plates was performed using a load-controlled FSW machine. Two types of welding tool materials were used in this study, namely, a $\mathrm{Si}_{3} \mathrm{~N}_{4}$-based material and a WC-Co-based material. For FSW with $\mathrm{Si}_{3} \mathrm{~N}_{4}$, fullpenetrated and defect-free butt welding joints were successfully produced. On the other hand, for FSW with WC-Co, the tool was deformed and the stir zone did not completely reach the bottom. The stir zone produced by the $\mathrm{Si}_{3} \mathrm{~N}_{4}$ tool showed a Vicker's hardness higher than the base metal and displayed a fine microstructure due to recrystallization. The yield strength and the tensile strength of the welds produced by the $\mathrm{Si}_{3} \mathrm{~N}_{4}$ tool exceeded that of the base metal.
\end{abstract}

Key Words : Electro-slag remelting methods, Friction stir welding, Butt-welding, Austenite, $\alpha$ formation

\section{INTRODUCTION}

Although high nitrogen-containing austenitic stainless steel (HNS) is known as a superior material, having high strength, high toughness, and high corrosion resistance, there are some problems to be solved. These include blowhole generation or nitride precipitation, caused by heat input during the welding process due to the high nitrogen content [1-6]. Thus, the application of a solid state joining process for HNS, which can be performed below its melting points, is significantly demanded $[7,8]$.

Friction stir welding (FSW), a new solid state welding process developed by TWI (The Welding Institute, England) in 1991 [9], is considered as an effective technique. However, reliable FSW HNS butt-welding joints have not yet been successfully obtained [8].

In this study, FSW was applied to HNS under various welding conditions. To examine the effect of the FSW tool on HNS steels, the performances of two types of welding tool materials, a WCCo-based material and a $\mathrm{Si}_{3} \mathrm{~N}_{4}$-based material, were investigated. To determine the optimum conditions to create reliable HNS FSW joints, the effect of welding parameters, i.e., the tool rotation speed, welding speed and the welding load on joint quality, were examined.

\section{EXPERIMENTAL PROCEDURE}

\subsection{Test materials}

The material used in this study was 1 mass $\%$ nitrogen-containing austenitic stainless steel (HNS) produced by pressurized electroslag remelting methods (ESR) [10]. Its chemical composition was
Table 1 FSW conditions applied in this experiment.

\begin{tabular}{|c|c|c|c|}
\hline & Tool Materials & Rotation Speed $(\mathrm{rpm})$ & Welding Speed $(\mathrm{mm} / \mathrm{min})$ \\
\hline \hline Condition A & $\mathrm{Si}_{3} \mathrm{~N}_{4}$ & 400 & 200 \\
\hline Condition B & WC-Co & 400 & 100 \\
\hline
\end{tabular}

Fe-23Cr-0Ni-1Mo-1 N (mass\%). The plates were $2 \mathrm{~mm}$ thick, $30 \mathrm{~mm}$ wide and $300 \mathrm{~mm}$ long.

\subsection{Welding conditions}

Butt-welding experiments were performed using a load controlled FSW machine. Two types of welding tools, $\mathrm{Si}_{3} \mathrm{~N}_{4}$ and WC-Co based materials were used. A water-cooled holder was installed and argon gas was employed to prevent oxidation of the plates. The conditions utilized in this study are listed in Table 1.

\subsection{Metallurgical inspections}

The joints were evaluated on the basis of surface appearance,

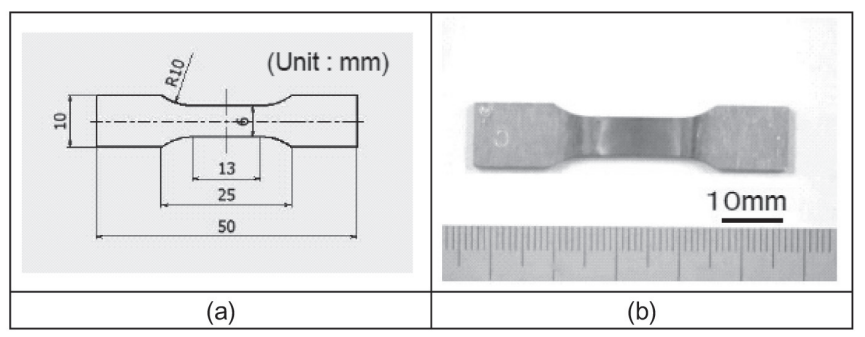

Figure 1 Configuration of transverse tensile specimen used in this study. (a) Specifications (b) Appearance 
macrostructure and microstructure observation. The metallurgical inspections were performed on a cross section of the joint after polishing and etching with aqua regia.

\subsection{Evaluation of joints properties}

The mechanical properties were evaluated using the Vicker's hardness test and transverse tensile test. The hardness profiles of the transverse section of the joints were measured in the middle section of the welded plates with a load of $4.9 \mathrm{~N}$ for $15 \mathrm{~s}$. The transverse tensile specimens were cut perpendicular to the welding directions, as shown in Figure 1 (a). Configuration of a tensile specimen is shown in Figure 1 (b). Before the test, the specimen was thoroughly mechanically treated to remove any ripples and flash. The tensile tests were carried out at room temperature at a crosshead speed of $1 \mathrm{~mm} / \mathrm{s}$. After the test, the fracture surfaces were examined using a scanning electron microscopy (SEM). The crystal structures of the base metal and the stir zone were identified by XRD.

\section{RESULT AND DISCUSSIONS}

In FSW joints produced under Condition A (Table 1), defects, such as voids and cracks, were not observed on the surface. The top surfaces was very smooth and there were almost no protrusions or depressions. On the other hand, in joints under Condition B, tool deformation was observed during welding process, and the stir zone did not penetrate to the bottom.

The low magnification cross sections of a FSW joint under Condition A are shown in Photo. 1. The left and right sides of the weld are consistent with the advancing and retreating sides, respectively. The stir zone is clearly observed to have thoroughly penetrated to the backing side. The presence of a high degree of continuity and no defects in the weld interior indicate the production of a sound weld joint.

The optical micrographs of 3 regions (labeled A, B and C shown in Photo. 1) are presented in Photo. 2. Region A is located on the weld center, region $\mathrm{B}$ is on the border of the stir zone and the heat affected zone (HAZ), and region $\mathrm{C}$ is on the base metal. The average grain size of the base metal is estimated to be more than $100 \mu \mathrm{m}$. On the other hand, the size of grain is extremely fine in the stir zone. This was the result of dynamic recrystallization during

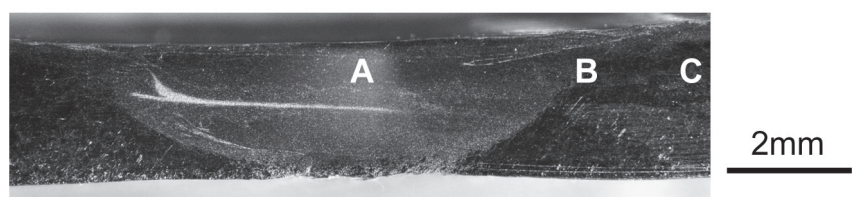

Photo 1 Cross section images of the friction stir welding joints of Condition A.
FSW.

The hardness profiles across the stir zones of the welded joints are shown in Figure 2. The hardening of the stir zone in HNS during the FSW was also observed in this study [8]. The stir zone exhibits about a 1.5 times higher hardness than the base metal. No significant differences in hardness were observed for the two conditions. A good relationship between the increase in hardness and the refinement of the grain were observed in this study.

The stress and elongation relationship of weld samples are shown in Figure 3. Both weld samples show higher strength than the base metals. The tensile strength and the yield strength of joints of Condition A show the highest values. However, the elongation of joints of Condition $\mathrm{A}$ is inferior to that of Condition B.

SEM observations of the fracture surfaces of the weld joints and the base metal are shown in Photo 3. The base metal shows a clear dimple pattern over the entire viewing field. Although fractures occurred in the HAZ in both Conditions A and $\mathrm{B}$, the fracture

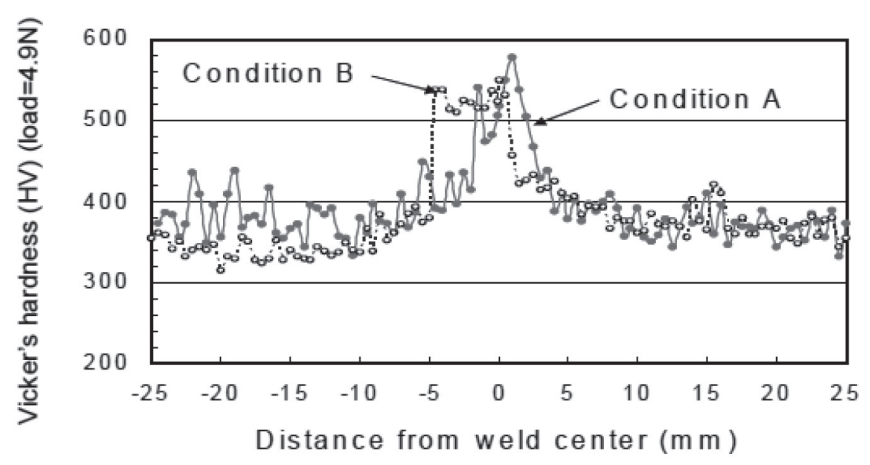

Figure 2 Hardness distribution of friction stir welding joints.

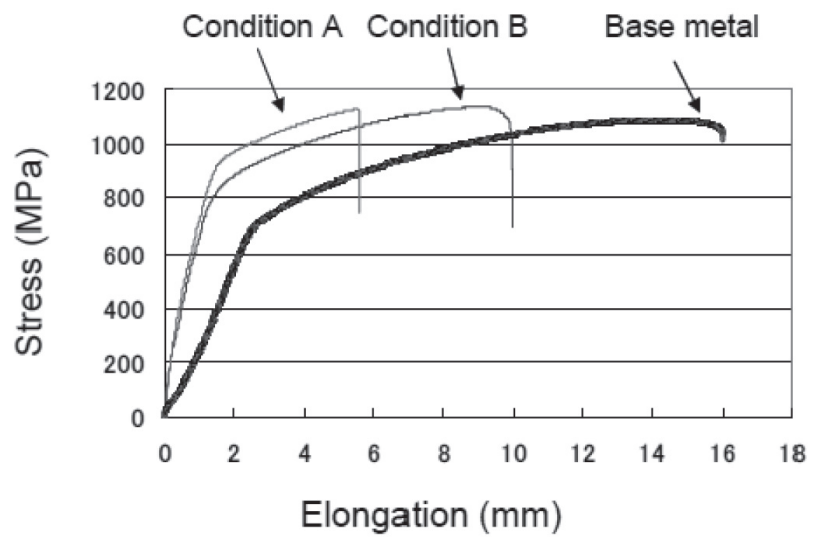

Figure 3 The stress and elongation relationship of the HNS friction stir welding joints.

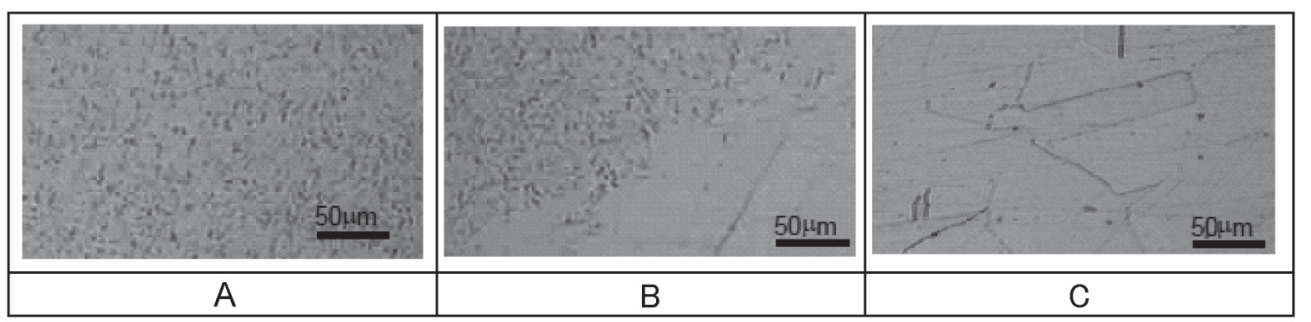

Photo 2 Optical microstructures of regions A, B and C shown in Figure 2. 
morphology is completely different. The fracture surface of the joints under Condition A shows a small dimple relateing to the fine grain. On the other hands, fracture surface of Condition B shows the characteristic feature of brittle fracture failure. The difference in failure fracture shown here is probably due to the $\alpha$ phase formation identified in Figure 4.

Figure 5 shows typical changes in the temperatures of the work piece during the process. Thermocouples were embedded on the

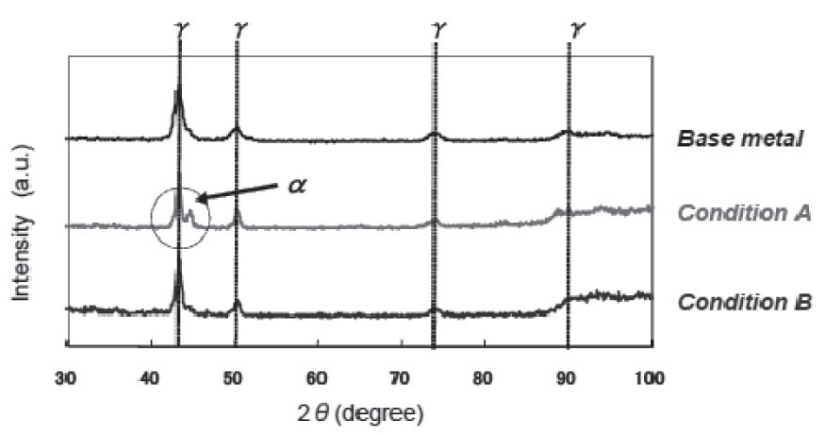

Figure 4 XRD patterns of the base metal and the fractured surface of FSW joints.

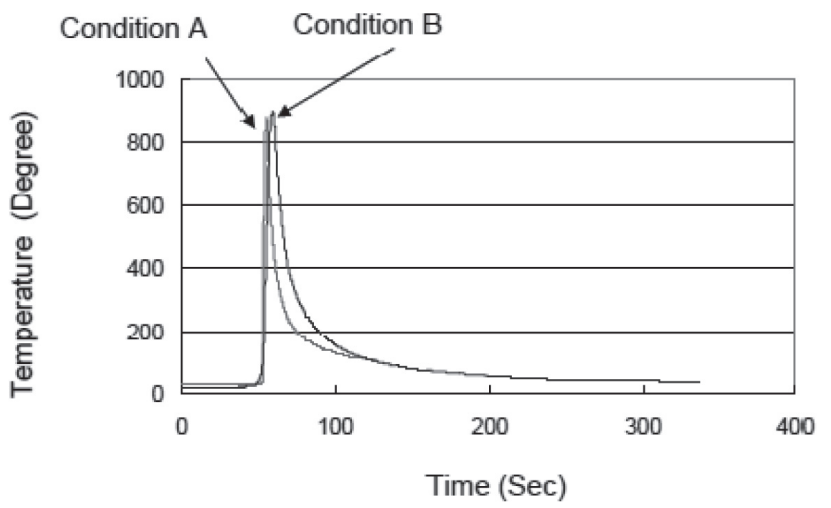

Figure 5 Temperature cycles for thermocouples located on the bottom surface. bottom surface at the center line [11], thus the temperature in the upper zone should be higher than the measured value. In this case, the peak temperatures under Condition B showed a higher value than that of Condition A. Although the difference recorded here is small, it was suspected that the FSW under Condition B was performed in $\alpha$ formation zone shown in Figure 6. This suggests that the temperature should exceed that of $\alpha$ formation zone to produce sound HNS joints..

\section{CONCLUSION}

Friction stir welding to obtain butt-welding joints of 1 mass $\%$ nitrogen-containing austenitic stainless steel was successfully performed without welding defects and tool deformation utilizing $\mathrm{Si}_{3} \mathrm{~N}_{4}$ under the condition of the rotation speed at $400 \mathrm{rpm}$ and the welding speed at $200 \mathrm{~mm} / \mathrm{min}$. The stir zones consist of very fine grain structures and show an increase in the Vicker's hardness. These joints also show higher tensile strength and yield strength than the base metals. The present study shows that FSW is an efficient joining process to join HNS with sound quality.

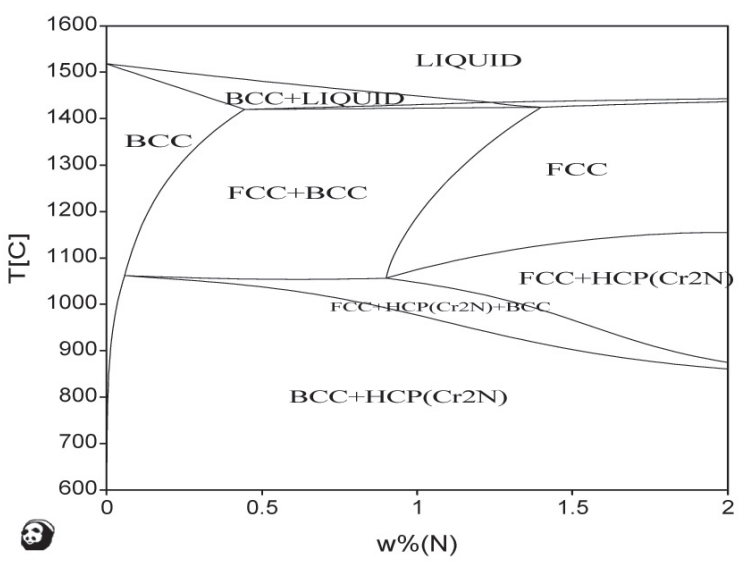

Figure 6 Thermo dynamics phase diagram of HNS(Fe-23Cr-1Mo$\mathrm{xN}$ )depending on nitrogen contents, calculated by the multicomponent phase diagram calculation software: Pandat, Materials Design Technology Co., Ltd..

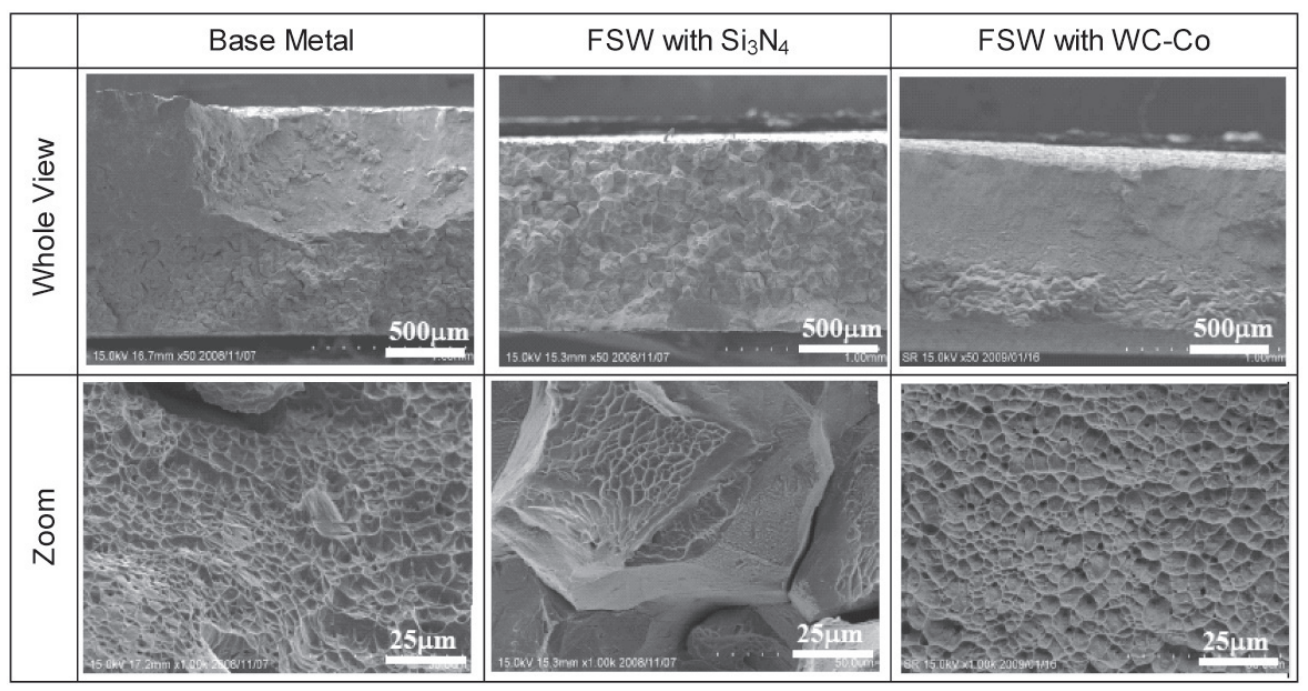

Photo 3 SEM images of the fracture surfaces of the base metal and the FSW joints. 


\section{Acknowledgements}

The authors wish to thank Mr. M. Kato, Akita Industrial Research Institute, and Mr. R. Kato, Akita University, for their technical assistance. The financial supports from the Japanese Ministry of Education, Science, Sports and Culture with a Grantin-Aid for Young Scientists (Start-up, No.20860019-00) and a Grant-in-Aid for Scientific Research (B) (No.00247230) are gratefully acknowledged.

\section{Reference}

[1] O. Kamiya, Z. W. Chen, Y. Kikuchi and T. Ohyoshi: Weldability Study of High Nitrogen Austenitic Stainless Steels Proceedings of Int. Conf. on AMDP2002, SD-file, Metal-paper 3-10. SD-file, Metal-paper 3-10, (2002).

[2] O. Kamiya, Y. Kikuchi and Z. W. Chen., "Welding of High Nitrogen Stainless Steel and the Microstructure on Fracture Toghness of the welds", Proceeding of ICMR Akita, 215-220, (2001).

[3] I. Woo, Y. Kikuchi., "Welderbility of High Nitrogen Stainless Steel", ISIJ International, 42-12: 1334-1343, (2002).

[4] T. Ogawa, K. Hiraoka, Y. Katada, M. Sagara and C. Shiga., "Nitride Precipitation Behavior of High Nitrogen-bearing Stainless HAZ and its Corrosion Resistance: Study on Properties of Welded Joints for High Nitrogen-bearing Stainless Steel", Q. J. Japan Welding Soc., 20-1: 96-104, (2002).
[5] T. Ogawa, K. Hiraoka, Y. Katada, M. Sagara S. Tsukamoto and C. Shiga., "Nitride Precipitation Behavior of High Nitrogen-bearing Stainless HAZ and its Corrosion Resistance: Study on Properties of Welded Joints for High Nitrogen-bearing Stainless Steel", Q. J. of Japan Welding Soc., 20-1: 107-113, (2002).

[6] I. Woo, T. Horinouchi, Y. Miyano and Y. Kikuchi., "Role of precipitated $\mathrm{Cr}_{2} \mathrm{~N}$ on the HAZ impact toughness of High-nitrogen Ni-free stainless steel. J. Steel and Related Materials", 2: 187-196, (2004).

[7] I. Woo, M. Aritoshi and Y. Kikuchi., "Metallugical and Mechanical Properties of High Nitrogen Stainless Steel Friction Welding", ISIJ Intern., 42-4: 401-406, (2002).

[8] S.H.C. Park, Y.S. Sato, H. Kokawa, K. Okamoto, S. Hirano and M. Inagaki., "Microstructure of Friction-Stir-Welded High Nitrogen Stainless Steel", Materials Science Forum, 539-543: 3757-3762, (2007).

[9] W. M. Thomas, E. D. Nicholas, J. C. Needhman, M. G. Murch, P. Temple-Smith and C. J. Dawes., International Patent Application PCT/GB92/02203 and GB Patent Application 9125978.8, UK Patent Office, London, Decwmber 6, (1991).

[10] W. Holzgruber., Austrian Pat. No. 333.327", S12, (1974).

[11] L. Cui, H. Fujii, N. Tsuji and K. Nogi., "Friction Stir Welding of a High Carbon Steel", Scripta Mater., 56: 637-640, (2007). 